\title{
Evaluación de la Actividad Antimicrobiana de Extractos de Propóleos de la Huasteca Potosina (México)
}

\author{
María L. Carrillo, Laura N. Castillo y Rosalba Mauricio \\ Unidad Académica Multidisciplinaria Zona Huasteca de la Universidad Autónoma de San Luis \\ Potosí. Calle Romualdo del Campo \# 501 Fracc. Rafael Curiel. Ciudad Valles, San Luis Potosí, \\ México (e-mail: maluisa@uaslp.mx)
}

Recibido Dic. 15, 2010; Aceptado Ene. 28, 2011; Versión Final recibida Mar. 15, 2011

\begin{abstract}
Resumen
Se ha evaluado la actividad antimicrobiana de los extractos etanólicos y acuosos de propóleos recolectados en la Huasteca Potosina, en México. Se usaron cepas de microorganismos Gram negativos: Escherichia coli, Salmonella typhi y Klebsiella pneumoniae; y microorganismos Gram positivos: Staphylococcus aureus, Staphylococcus epidermidis y Streptococcus agalactiae. La concentración mínima bactericida $(\mathrm{CMB})$ de cada extracto se determinó con el método de dilución en tubo. La CMB del extracto etanólico fue $0.93 \mathrm{mg} \mathrm{mL}^{-1}$ para las Gram positivas y $7.5 \mathrm{mg} \mathrm{mL}^{-1}$ para las Gram negativas; en el extracto acuoso fue $20 \mathrm{mg} \mathrm{mL}^{-1}$ para Gram positivas y $30 \mathrm{mg} \mathrm{mL}^{-1}$ para Gram negativas. Los extractos etanólicos del propóleo tienen una actividad antibacteriana significativamente mayor que los extractos acuosos, y esta actividad depende de su procedencia y de la especie bacteriana evaluada.
\end{abstract}

\section{Evaluation of Antimicrobial Activity of Extracts of Huasteca Potosina Propolis}

\begin{abstract}
The antimicrobial activity of ethanolic and aqueous extracts of propolis in the Huasteca Potosina, in Mexico was evaluated. Strains of Gram negative: Escherichia coli, Salmonella typhi and Klebsiella pneumoniae, and Gram positive microorganisms: Staphylococcus aureus, Staphylococcus epidermidis and Streptococcus agalactiae, were used. The minimum bactericidal concentration (MBC) of each extract was determined by the tube dilution method. The ethanol extract was significantly more inhibitory than the aqueous $(p \leq 0.05)$. The ethanol extract CMB was $0.93 \mathrm{mg}$ $\mathrm{mL}-1$ for Gram-positive and $7.5 \mathrm{mg} \mathrm{mL}-1$ for Gram negative, in the aqueous extract was $20 \mathrm{mg}$ $\mathrm{mL}-1$ for Gram-positive and $30 \mathrm{mg} \mathrm{mL}-1$ for Gram negative. The ethanol extracts have higher antibacterial activity compared with aqueous extracts, and antibacterial activity depends on its origin and on the bacterial species evaluated.
\end{abstract}

Keywords: propolis, antibacterial activity, Gram microorganisms, bactericidal concentration 


\section{INTRODUCCIÓN}

La utilización de productos naturales con fines curativos es importante, se ha transmitido de generación en generación, y frecuentemente se usan extractos de plantas o de árboles. El propóleo es un producto natural, resinoso, verde pardo, castaño o incluso casi negro, según su origen botánico, y es elaborado por las abejas con la secreción que ellas recogen de álamos (Populus alba), sauces (Salix babilonica), abedules (Betula allegheniensis), alisos (Alnus sp.), castaños silvestres (Castanea sativa), pinos (Pinus sp.), enebros (Juniperus communis) y algunas plantas herbáceas (Salamanca, 2005). Las abejas lo usan para proteger sus apiarios del ataque de insectos, para cubrir el interior de la caja de la colmena y evitar las corrientes de aire, y para controlar la temperatura en su colonia.

En la región de la Huasteca Potosina, en México, la apicultura es una actividad económica cuyo producto principal es la miel y como subproducto el propóleo con el cual se elaboran compuestos terapéuticos, principalmente para infecciones de las vías respiratorias. El propóleo de esta región tiene su origen botánico en la planta de caña de azúcar (Saccharum officinarum) y árboles de cítricos. Al propóleo se le atribuyen poder antiséptico, desinfectante y antihelmíntico (Reichling, 1990; Bankova et al., 2000). Así mismo, el propóleo es usado como antifúngico, citostático, antioxidante y antiinflamatorio (Scheller et al., 1990), para el tratamiento de afecciones provocadas por diferentes microorganismos (González y Bernal, 1997).

Algunos autores (Kujumgiev et al., 1999; Hegazi y El Hady 2002.) indican una actividad antibacterial del propóleo contra Enterococcus sp, Escherichia coli, y Staphylococcus aureus. Los propóleos de las abejas africanizadas presentan mayores halos de inhibición contra el $\mathrm{S}$. aureus que los de abejas europeas (Moura et al., 1999); en propóleos argentinos, 50 \% de las muestras inhibieron en más de $12 \mathrm{~mm}$ cepas de $S$. aureus y el diámetro del halo de inhibición dependió del contenido de flavonoides en los extractos etanólicos del propóleo (EEP) (Chaillou et al., 2004; Lotti et al., 2010). No obstante, Manrique y Santana (2004) reportan halos de inhibición de 11 a $25 \mathrm{~mm}$ contra las bacterias S. aureus y Micrococcus luteus, aunque los EEP mostraron $0.19 \%$ a $0.32 \%$ de flavonoides y elevada actividad antioxidante. Vargas et al. (2004) reportan que los EEP mostraron actividad antimicrobiana contra una serie de bacterias e inhibieron 45 aislados de Staphylococcus sp. Según Orsi et al. (2005), los EEP tienen efecto bactericida contra Salmonella enteritidis y S. typhimurium, y el poder bactericida de propóleos contra bacterias Gram negativas varía según la región geográfica de producción (Bedascarrasbure et al. (2000), ya que el ambiente ejerce influencia en el contenido de compuestos fenólicos, a los cuales se le atribuyen las propiedades antimicrobianas del propóleo (Anttonen y Karjalainen, 2005).

En la Huasteca Potosina se consumen extractos de propóleo cuya actividad antimicrobiana no ha sido científicamente evaluada, lo cual es necesario para usar los compuestos naturales con mayor confianza por parte de la población, ya que tales productos se ofrecen a un costo menor que los productos farmacéuticos que se encuentran en el mercado. Aunque este tema ha sido abordado por otros autores, se ha reportado que la actividad antimicrobiana del propóleo depende de sus componentes, los cuales varían en su composición química, según la región y la estación de recolección (Sforcin et al., 2000;Tolosa y Cañizares, 2002). Por lo anterior, el objetivo de este trabajo fue evaluar la actividad antibacteriana de la Huasteca Potosina y analizar el efecto que tienen la procedencia y el tipo de extracto sobre el crecimiento de bacterias Gram negativas y Gram positivas.

\section{MATERIALES Y MÉTODOS}

\section{Obtención y preparación de extractos}

Se usaron cuatro muestras de propóleo de apiarios localizados en la Huasteca Potosina: Ejido Laguna del Mante, Los Sabinos, La Loma y Tamazunchale, efectuando el procedimiento descrito a continuación por triplicado. Se pesaron $20 \mathrm{~g}$ de propóleo, se envolvieron en papel filtro y se colocaron en el cuerpo intermedio de un equipo Soxhlet, que es la parte donde se lleva a cabo la extracción, mientras que en el matraz balón del mismo equipo, se colocaron $200 \mathrm{~mL}$ de etanol al 
$80 \%$ o de agua -según si el extracto fue etanólico o acuoso-, y se sometieron a reflujo por $1 \mathrm{~h}$. Se detuvo el reflujo y la muestra se filtró a través del papel filtro Whatman No. 40; separando el filtrado y el sólido residual. El sólido residual se sometió nuevamente a reflujo durante una hora con $200 \mathrm{~mL}$ del solvente correspondiente. El nuevo filtrado se reunió con el anterior, constituyendo esto el extracto final. La preparación de estos extractos se hizo por triplicado. Los extractos totales finales se transfirieron al matraz de un rotavapor (marca Büchi) y se mantuvieron en evaporación hasta la desaparición del solvente. En este caso, la temperatura que se usó en el rotavapor fue de $40^{\circ} \mathrm{C}$, haciendo más rápida la recuperación del solvente. En general, el tiempo para cada extracción fue de $1 \mathrm{~h}$ y 30 minutos considerando también el tiempo en que la muestra se mantuvo a reflujo. El sólido obtenido se secó 2 h en estufa a $70{ }^{\circ} \mathrm{C}$, para eliminar residuos de solvente y obtener el extracto total.

El rendimiento de cada muestra de propóleo se calculó de acuerdo a la ecuación 1.

$R(\%)=P .100 / m$

donde, $\mathrm{R}$ es el rendimiento en porcentaje, $\mathrm{P}$ el peso del extracto $(\mathrm{g})$ y $\mathrm{m}$ el peso de la muestra.

A partir de cada extracto de propóleo, se pesaron $6 \mathrm{~g}$ y se aforaron a $100 \mathrm{~mL}$ de agua destilada, obteniendo soluciones de extracto de propóleo con una concentración de $6 \%\left(60 \mathrm{mg} \mathrm{mL}^{-1}\right)$. Para esterilizar las soluciones de los extractos, éstas se filtraron a través de membranas con poros de $0.45 \mu \mathrm{m}$, y se colocaron en frascos de plástico estériles. Las soluciones preparadas se almacenaron a $10^{\circ} \mathrm{C}$ hasta su uso.

\section{Evaluación de la actividad antibacteriana}

La evaluación del efecto antibacteriano de los diferentes extractos sobre las especies bacterianas, se realizó mediante el método de dilución en tubo reportado por Chiang et al. (1985), el cual continúa siendo un método sencillo que permite observar el desarrollo o inhibición del crecimiento microbiano. Se preparó una serie de tubos en la cual el primero contenía $2 \mathrm{~mL}$ de caldo nutritivo a doble concentración y los demás contenían la misma cantidad de caldo a simple concentración. Al primer tubo se le añadieron $2 \mathrm{~mL}$ de extracto de propóleo al $6 \%\left(60 \mathrm{mg} \mathrm{mL}^{-1}\right)$, de éste se tomó una alícuota de $2 \mathrm{~mL}$ que se añadió al tubo siguiente, procediendo así con los tubos restantes hasta desechar los últimos $2 \mathrm{~mL}$, de tal forma que la concentración del extracto de propóleo en cada tubo quedó como se muestra en la Tabla 1.

Tabla 1: Concentraciones en $\left(\mathrm{mg} \mathrm{mL}^{-1}\right)$ del extracto de propóleo obtenidas en las diferentes diluciones. El símbolo * significa que se usó agua destilada estéril.

\begin{tabular}{|c|c|c|c|c|c|c|c|c|c|c|c|}
\hline Tubos & 1 & 2 & 3 & 4 & 5 & 6 & 7 & 8 & 9 & 10 & Testigo \\
\hline Dilución & $1 / 2$ & $1 / 4$ & $1 / 8$ & $1 / 16$ & $1 / 32$ & $1 / 64$ & $1 / 128$ & $1 / 256$ & $1 / 512$ & $1 / 1024$ & $*$ \\
\hline Concentración & 30 & 15 & 7.5 & 3.75 & 1.87 & 0.93 & 0.46 & 0.23 & 0.11 & 0.05 & 0 \\
\hline
\end{tabular}

Paralelamente se corrió una serie de tubos sólo con agua destilada estéril realizándose las diluciones correspondientes. Cada serie se inoculó con $0.1 \mathrm{~mL}$ de una suspensión bacteriana de cepas correspondientes al cepario del Laboratorio de Microbiología de la Unidad Académica Multidisciplinaria Zona Huasteca de la Univ. Autónoma de San Luis Potosí. Los microorganismos empleados fueron: Escherichia coli, Klebsiella pneumoniae, Salmonella typhi, Staphylococcus aureus ATCC 6538, Staphylococcus epidermidis y Streptococcus agalactiae, cuya concentración de UFC $\mathrm{mL}^{-1}$ correspondió al tubo 3 de la escala de Mc Farland $\left(9 \times 10^{8}\right.$ células $\left.\mathrm{mL}^{-1}\right)$ (Díaz et al., 1999), y se incubaron $24 \mathrm{~h}$ a $37^{\circ} \mathrm{C}$. Después se tomó una asada y se inocularon en los medios de cultivo selectivos: agar Mac Conckey para E. coli y Klebsiella pneumoniae, agar Baird Parker para S. aureus, agar salmonella-shigella para S. typhi, agar sangre para S. epidermidis y para $S$. agalactiae (Merck, 2000). La presencia de las bacterias en estos medios indicó que el extracto de 
propóleo utilizado no inhibió su crecimiento; por el contrario, si no se observó crecimiento, indicó que el extracto de própoleo sí tuvo actividad antimicrobiana.

\section{Análisis de resultados}

Los rendimientos promedio de sólidos solubles totales de las tres réplicas realizadas para los extractos etanólicos y acuosos de las cuatro muestras de propóleo estudiadas, se compararon con la prueba $t$ de Student $(p \leq 0.01)$. Para determinar la dependencia de la actividad antimicrobiana con la procedencia de los propóleos, el tipo de extracto y la especie bacteriana sobre la cual actúan, se empleó un diseño factorial de bloques aleatorizados. El análisis de los resultados se hizo mediante un análisis de regresión múltiple ( $p \leq 0.05)$, usando el programa GraphPad InStat 3.

\section{RESULTADOS Y DISCUSIÓN}

Los extractos etanólicos de propóleo fueron café claro, y los extractos acuosos café oscuro, independientemente de la procedencia del propóleo. El color en ambos extractos se atribuyó a la presencia de compuestos tipo flavonoide (Walker y Crane, 1987). En la Tabla 2 se muestra el porcentaje de sólidos solubles totales (rendimiento) obtenido con las muestras de propóleo. El rendimiento fue mayor en los extractos acuosos que en los extractos etanólicos, lo cual se atribuyó a que al eliminar los residuos del solvente en el extracto húmedo, el agua no se eliminó en la misma proporción que el etanol. Sin embargo, con la prueba t de Student no se encontró una diferencia significativa entre los rendimientos. Estos datos difieren a los obtenidos por Tolosa y Cañizares (2002), quienes obtuvieron valores superiores en el total de sólidos extraídos con el etanol que al utilizar agua como solvente. En ambos extractos el mayor rendimiento correspondió a las muestras procedentes del Ejido de Laguna del Mante y del Ejido La Loma.

Tabla 2: Resultados de los rendimientos (\%) de los extractos etanólico y acuoso de propóleo. El símbolo * significa que no hubo diferencias significativas ( $p>0.01)$.

\begin{tabular}{|c|c|c|}
\hline \multirow{2}{*}{ Muestra de propóleo } & \multicolumn{2}{|c|}{ Rendimiento (\%) } \\
\cline { 2 - 3 } & Extracto etanólico & Extracto acuoso \\
\hline 1, Ejido Laguna del Mante & $55( \pm 6.93)$ & $85( \pm 21.66)$ \\
\hline 2, Ejido Los Sabinos & $35( \pm 2.52)$ & $41( \pm 2.00)$ \\
\hline 3, Tamazunchale & $33( \pm 1.00)$ & $43( \pm 0.58)$ \\
\hline 4, Ejido La Loma & $44( \pm 1.00)$ & $48( \pm 1.00)$ \\
\hline Rendimiento & $41.83^{*}$ & $51.83^{*}$ \\
\hline
\end{tabular}

Los resultados de la actividad antibacteriana de los extractos de propóleo se muestran en la Tabla 3. En general, el extracto etanólico fue más inhibitorio que el acuoso. La CMB del extracto etanólico fue $0.93 \mathrm{mg} \mathrm{mL}^{-1}$ para las Gram positivas -siendo $S$. aureus la bacteria más susceptible, ya que requirió de una menor $\mathrm{CMB}$ para ser inhibida-, y $7.5 \mathrm{mg} \mathrm{mL}^{-1}$ para las Gram negativas, mientras que la CMB del extracto acuoso fue de $20 \mathrm{mg} \mathrm{mL}^{-1}$ para Gram positivas y $30 \mathrm{mg} \mathrm{mL}^{-1}$ para Gram negativas, aunque hubo algunas variaciones dependiendo del tipo de bacteria, que se atribuyeron a las características intrínsecas existentes entre las distintas especies bacterianas.

En general, las cepas bacterianas mostraron menor susceptibilidad a los extractos acuosos que a los extractos etanólicos. La CMB promedio de los extractos etanólicos tuvo un valor más bajo (14.75 mg mL $\left.\mathrm{m}^{-1}\right)$ que el de los extractos acuosos $\left(27.5 \mathrm{mg} \mathrm{mL}^{-1}\right)$, demostrándose que los extractos etanólicos tienen mayor efectividad antibacteriana. El análisis de regresión múltiple mostró que tanto la procedencia del propóleo, el tipo de extracto utilizado, así como la especie de microorganismo evaluado afectan la CMB del propóleo (Tabla 4). 
Tabla 3: Valores de la CMB de los extractos etanólico (E) y acuoso (A) de propóleo sobre E. coli, S. aureus, K. pneumoniae, S. typhi, S, epidermidis y Streptococcus agalactiae. SI significa "Sin Inhibición”. 1 Ejido Laguna del Mante. 2 Ejido Los Sabinos. 3 Tamazunchale. 4 Ejido La Loma.

\begin{tabular}{|c|c|c|c|c|c|c|}
\hline \multirow{2}{*}{$\begin{array}{c}\text { Procedencia } \\
\text { del propóleo }\end{array}$} & \multicolumn{6}{|c|}{$\mathrm{CMB}\left(\mathrm{mg} \mathrm{mL}^{-1}\right)$} \\
\cline { 2 - 7 } & S. aureus & S. epidermidis & S. agalactiae & E. coli & S. typhi & K. pneumoniae \\
\hline 1 E & $20( \pm 7.07)$ & $10( \pm 3.54)$ & $20( \pm 7.07)$ & $22( \pm 9.61)$ & $15( \pm 0.00)$ & $20( \pm 8.66)$ \\
1 A & SI & SI & SI & SI & SI & SI \\
\hline 2 E & $2.5( \pm 1.09)$ & $15( \pm 0.00)$ & $25( \pm 8.66)$ & $10( \pm 4.33)$ & $20( \pm 8.66)$ & $20( \pm 8.66)$ \\
2 A & SI & $30( \pm 0.00)$ & SI & SI & SI & SI \\
\hline 3 E & $0.93( \pm 0.00)$ & $1.87( \pm 0.00)$ & $5.0( \pm 2.17)$ & $7.5( \pm 0.00)$ & $10( \pm 4.33)$ & $10( \pm 4.33)$ \\
3 A & $20( \pm 8.66)$ & $25( \pm 8.66)$ & $30( \pm 0.00)$ & $30( \pm 0.00)$ & $\mathrm{SI}$ & $30( \pm 0.00)$ \\
\hline 4 E & $25( \pm 8.66)$ & $30( \pm 0.00)$ & $30( \pm 0.00)$ & $\mathrm{SI}$ & $\mathrm{SI}$ & $\mathrm{SI}$ \\
4 A & $\mathrm{SI}$ & $\mathrm{SI}$ & $\mathrm{SI}$ & $\mathrm{SI}$ & $\mathrm{SI}$ & $\mathrm{SI}$ \\
\hline
\end{tabular}

Tabla 4: Análisis de regresión múltiple: $y=6.499+0.495(A)-5.95(B)-0.513(C) ; R^{2}=0.99 ; F=$ $10010.04 ; p \leq 0.0001$

\begin{tabular}{|l|c|c|c|c|}
\hline \multicolumn{1}{|c|}{ Variable } & Coeficiente & Error estándar & Infrerior 95\% & Superior 95\% \\
\hline Constante & 6.499 & 0.0319 & 6.435 & 6.564 \\
\hline Procedencia (A) & 0.495 & 0.0029 & 0.489 & 0.501 \\
\hline Tipo de extracto (B) & -5.955 & 0.0358 & 5.882 & 6.027 \\
\hline Especie bacteriana (C) & -0.5135 & 0.0202 & 0.4727 & 0.554 \\
\hline
\end{tabular}

Los resultados obtenidos en este trabajo son similares a los de Tolosa y Cañizares (2002) en el que indican que existe un efecto bactericida tanto del extracto etanólico como del acuoso frente a bacterias Gram positivas. Determinaron que el extracto etanólico de propóleo es efectivo contra las bacterias Gram positivas (Streptococcus pyogenes y S. aureus) y Gram negativas (S. typhi y Pseudomonas aeruginosa), al obtener una CMB de $0.93 \mathrm{mg} \mathrm{mL}^{-1}$ en ambos tipos de bacterias, en cambio el extracto acuoso frente a las bacterias Gram positivas requirió una CMB de $3.75 \mathrm{mg} \mathrm{mL}^{-}$ 1 , y contra las Gram negativas la CMB fue de $15 \mathrm{mg} \mathrm{mL}^{-1}$ lo que hace al extracto acuoso menos inhibitorio que el etanólico. A diferencia de esos resultados, en este trabajo las CMB del extracto etanólico fueron de $0.93 \mathrm{mg} \mathrm{mL}^{-1}$ para las Gram positivas y $7.5 \mathrm{mg} \mathrm{mL}^{-1}$ para las Gram negativas, mientras que con el extracto acuoso fueron de 15 y $30 \mathrm{mg} \mathrm{mL}^{-1}$ para las Gram positivas y Gram negativas respectivamente. El requerir una CMB menor de extracto etanólico que de extracto acuoso se atribuye a que es en la fracción etanólica donde existe una mayor cantidad de flavonoides, -compuestos fenólicos a los que se les atribuye actividad antibacteriana (Brushi et al., 2003)-, por ser éstos solubles en solventes polares como el etanol. Aunque los flavonoides son solubles en agua, su solubilidad va a depender de la cantidad de heterósidos fenólicos presentes en el propóleo, y la composición de éste depende de los sitios de recolección (Kumazawa et al., 2007).

Considerando la procedencia de los propóleos estudiados, en este trabajo, el procedente de Tamazunchale, se consideró con mayor actividad antimicrobiana debido a que la CMB para las bacterias estudiadas fue menor que la de los otros extractos. Así mismo, Moreno et al. (2007) 
utilizaron extracto etanólico de propóleo proveniente de Argentina, Colombia y Cuba frente a una bacteria Gram positiva (Streptococcus mutans), dando un mejor resultado el extracto de propóleo de Colombia con una CMB de $0.02 \mathrm{mg} \mathrm{mL}^{-1}$.

De las bacterias estudiadas, $S$. aureus requirió de una menor CMB que las demás, lo que coincide con Sanabria-Galindo et al. (2002) que determinaron una potente actividad antibacteriana al utilizar extracto etanólico contra bacterias Gram positivas (Bacillus subtillis y S. aureus) con una CMB de 0.010 y $0.175 \mathrm{mg} \mathrm{mL}^{-1}$, respectivamente; también utilizaron bacterias Gram negativas $(E$. coli, S. typhi y K. pneumoniae) pero en estas no se observó actividad antibacteriana. Estos resultados difieren de los obtenidos en este trabajo, ya que aunque se requirió de una mayor concentración de extracto para inhibir el crecimiento de las bacterias Gram negativas, éstas sí se inhibieron. Aunque los trabajos reportados no explican la causa de una mayor actividad bactericida del extracto de propóleo sobre las Gram positivas, esto podría deberse a las diferencias en la composición de las paredes celulares de cada grupo de bacterias. La pared celular en las Gram negativas está compuesta por varias capas y es bastante compleja, mientras que la pared en las Gram positivas está formada sólo por un tipo de molécula (Madigan et al., 2004). Esta diferencia puede contribuir a la susceptibilidad de este grupo de bacterias a la acción de los principios activos del propóleo.

\section{CONCLUSIONES}

Los extractos acuosos y etanólicos del propóleo tienen actividad antibacteriana. Esta actividad depende de la procedencia de los propóleos, del tipo de solvente empleado en su extracción y de la especie bacteriana sobre las cual se usan los extractos. Los extractos etanólicos tienen una mayor actividad antibacteriana en comparación con los extractos acuosos, siendo las bacterias Gram positivas más susceptibles que las bacterias Gram negativas, a los extractos etanólicos del propóleo.

\section{AGRADECIMIENTOS}

Las autoras agradecen a la Secretaría de Investigación y Posgrado de la Universidad Autónoma de San Luis Potosí, por el apoyo brindado a través del Fondo de Apoyo a la Investigación, para la realización de este trabajo.

\section{REFERENCIAS}

Antonen, J. M. y O. R. Karjalainen, Environmental and genetic variation of phenolic compound in red raspberry, J. Food Composition Anal., 18(8), 759-769 (2005).

Bankova, V., S. De Castro y M. Marccuci, Review of Propolis: recent advances in chemistry and plant origin, Apidologie, 31, 3-15 (2000).

Bedascarrasbure, E., L. Maldonado, C. Segura, O. Pérez, A. Álvarez, H. A. Vander, y A. Tabera, Caracterización de propóleos argentinos, II-Valle Calchaquí, Anales del Congreso Internacional de Propóleos, Buenos Aires, 103 (2000).

Brushi, M. L., S. L. Franco y M. P. Gremiao, Application of an HPLC method for analysis of propolis extract, J. Liquid Chromat. Related Tecnol., 26(14), 2399-2409 (2003).

Chaillou L.L., H.A. Herrera, y J.F. Maidana, Estudios de propóleos de Santiago del Estero, Argentina, Ciencia y Tecnología de Alimentos, 24(1), 11-15 (2004).

Chiang, R. B., A. C. Cuza, M. Concepción, J. Álvarez y D. Jiménez, Pruebas Microbiológicas para evaluar la efectividad bactericida de desinfectantes químicos. Instituto Nacional de Higiene, Epidemiología y Microbiología, La Habana, Cuba (1985).

Díaz, R., C. Gamazo y I. López-Goñi, Manual Práctico de Microbiología, $2^{a}$ edición, 45-48. Ed. Masson, Barcelona, España (1999). 
González, G. A. y M. R. Bernal, Propóleos: un camino hacia la salud, Ed. Pablo de la Torriente, La Habana, Cuba (1997).

Hegazi, A.G. y F. El-Hady, Egyptian propolis: antioxidant, antimicrobial activities and chemical composition of propolis from reclaimed lands, Z. Naturforsch., 57(3), 395-402 (2002).

Kujumgiev, A., I. Tsvetkova, Y. Serkedjieva, V. Bankova, R. Christov y S. Popov, Antibacterial, antifungal and antiviral activity of propolis of different geographic origin, J. Ethnopharm., 64, 235240 (1999).

Kumazawa, S., R. Ueda, T. Hamasaka, S. Fukumoto, T. Fujimoto y T. Nakayama, Antioxidant prenylated flavonoids from propolis collected in Okinawa, Japan, J. Agric. Food Chem., 55 (19), 7722-7725 (2007).

Lotti, C., M. Campo Fernandez, A. L. Piccinelli, O. Cuesta-Rubio, I. Márquez Hernández y L. Rastrelli, Chemical constituents of red mexican propolis, J. Agric. Food Chem., 58(4), 2209-2213 (2010).

Madigan, M. T., J. M. Martinko y J. Parker, Brock. Biología de los micororganismos, $10^{\mathrm{a}}$ edición, Ed. Pearson-Prentice Hall, Madrid, España (2004).

Manrique, A.J. y W.C. Santana, Antibacterial and antioxidant activities of propolis of native (Brazil and Venezuela) stingless bees (Melipona quadrifasciata Lep., Tetragonisca angustula and Nannotrigona sp.), Proc. $8^{\text {th }}$ IBRA International Conference on Tropical Bees and VI Encontro sobre Abelhas, Ribeirão Preto, Brasil (2004).

Merck, K., Microbiology Manual. Ed. Deutscher Akkreditierungs Rat. Berlin, Alemania (2000).

Moreno, Z. H., P. Martínez, y J. Figueroa, 2007. Efecto antimicrobiano in vitro de propóleos argentinos, colombianos y cubanos sobre Streptococcus mutans ATCC 25175, Univ. Nacional de Colombia, sede Bogotá, http://www.unicolmayor.edu.co/invest_nova/NOVA/NOVA7_70_75.PDF. (Consultado en julio de 2010).

Moura, F., M. Ikegaki, S. Alencar, H. Sato e Y. Park, Abelhas européias vs. abelhas africanizadas: Estudo comparativo de sua própolis. Revista da Universidade de Franca (Edição Especial) I Simpósio Brasileiro sobre própolis e Apiterápicos, 7(7), 44 (1999).

Orsi, R.O., J.M. Sforcin, V.L.M. Rall, S.R.C. Funari, L. Barbosa y J.R.A. Fernández, Susceptibility profile of Salmonella against the antibacterial activity of propolis produced in two regions of Brazil, J. Venomous Animals Toxins including Trop. Dis., 11(2), 109-116 (2005).

Reichling, J., Function of plant secondary metabolitos and their exploitation in biotechnology, Editorial Sheffield, Academic Press, Alemania (1990).

Salamanca, G., Propiedades nutricionales y apiterapéuticas de los productos de la colmena, Memorias I Congreso Internacional de Apicultores de los Andes y III Convención de Apicultores, 514, San Cristóbal, Táchira, Venezuela, (2005).

Sanabria- Galindo, A., L. A. Cárdenas, y M. L. Parroquiano, Actividad antimicrobiana y examen fotoquímico preliminar de siete angiospermas y una muestra de propóleo, Rev. Colombiana de Ciencias Químico Farmacéuticas, 31, 36-42 (2002).

Scheller, S., T. Wilczok, S. Imielski, W. Krol, J. Gabrys y J. Shani, Free radical scavenging by ethanol extract of propolis, Int. Radiat. Biol, 57 (46): 1-5 (1990). 
Sforcin, J.M., A. Fernández, C.A.M. Lopes, V. Bankova, and S.R.C. Funari, Seasonal effect on Brazilian propolis antibacterial activity, J. Ethnopharmacol., 73, 243-249 (2000).

Tolosa, L. y E. Cañizares, Obtención, caracterización y evaluación de la actividad antimicrobiana de extractos de propóleos de Campeche, Ars. Pharm., 43 (1), 187-204 (2002).

Vargas, A. C., A. P. Loguercio, N. M. Witt, M. M. da Costa, M. Sá e Silva, y L.R. Viana, Atividade antimicrobiana "in vitro" de extrato alcóholico de própolis, Ciencia Rural, 34(1), 159-163 (2004).

Walker, P., and E. Crane, Constituents of propolis, Apidologie, 18 (4): 327-334 (1987). 